\title{
DESCRIPTION OF TEXTURE AND YIELD LOCUS EVOLUTION UNDER DIFFERENT DEFORMATION PATHS OF COPPER SHEET
}

\author{
N. MINGOLO \\ Depto. Materiales, Gerencia Desarrollo, CNEA, Av. Libertador 8250, \\ 1429 Buenos Aires, Argentina \\ and \\ C. VIAL-EDWARDS \\ Escuela de Ingeniería, Pontificia Universidad Católica de Chile, \\ Vicuña Mackenna 4860, Santiago, Chile
}

(Received 13 March 1995)

\begin{abstract}
The evolution of texture with plastic deformation along different loading paths has been studied for a commercial DHP copper sheet metal. Two models have been utilized to predict the evolution of textures: Viscoplastic under Relaxed Constraints conditions (VRC) and a Self Consistent approach (SC) with viscoplastic conditions, where the $\{111\}<110>$ active slip systems were selected according to a strain rate sensitivity law.

The stress-strain curves along different loading paths were calculated taking into account the texture evolution predicted by VRC and SC models. Predictions with the SC formulation were very close to experimental results. Texture evolution depended on the deformation path.
\end{abstract}

KEY WORDS: Copper Sheet, Viscoplastic Model, Self Consistent Model, Yield Locus

\section{NOTATION}

$0^{\circ}, 45^{\circ}, 90^{\circ}$

$\tau_{\mathrm{k}}$

ns

$\dot{\gamma}^{\mathbf{k}}, \dot{\gamma}_{0}^{\mathbf{k}}$

$\tau^{k}, \tau_{0}^{k}$

$\tau$
$\dot{\epsilon}_{i j}$
$\sigma_{i j}$
$\dot{\mathrm{E}}_{\mathrm{ij}}$
$\Sigma_{\mathrm{ij}}$
$\mathbf{M}^{\mathrm{c}}$
$\mathbf{M}$
$\tilde{\mathbf{M}}$ angles to the rolling direction

resolved shear stress on the $\mathbf{k}$ slip system

inverse of the strain rate sensitivity exponent

shear strain rate and reference shear strain rate on the $k$ slip resolved shear stress and reference resolved shear stress on the $\mathrm{k}$ slip system

critical resolved shear stress

strain rate tensor of the grain

stress tensor of the grain

strain rate tensor of the polycrystal

stress tensor of the polycrystal

compliance modulus of the grain

compliance modulus of the polycrystal

interaction matrix 


\begin{tabular}{|c|c|}
\hline $\mathbf{S}$ & viscoplastic Eshelby tensor \\
\hline$\epsilon_{\mathrm{eq}}$ & equivalent strain \\
\hline$(-q)$ & ratio of transverse to longitudinal strain \\
\hline$\overline{\mathbf{M}}$ & average Taylor factor \\
\hline & grain orientation in Euler space \\
\hline$f(g)$ & Crystallite Orientation Function (ODF) \\
\hline $\mathrm{U}_{0}, \mathrm{U}_{45}, \mathrm{U}_{90}$ & flow stress in uniaxial tension tests at $0^{\circ}, 45^{\circ}$ and 90 \\
\hline $\mathrm{P}_{0}, \mathrm{P}_{90}$ & flow stress in quasi plane strain tension tests \\
\hline & flow stress in biaxial tension test \\
\hline & Lankford anisotropy coefficient \\
\hline $\mathrm{K}, \mathrm{n}$ & parameters in equation $\sigma=K \in^{n}$ \\
\hline
\end{tabular}

\section{INTRODUCTION}

The evolution of crystallographic textures with plastic deformation has an important effect on mechanical properties of metals and it may be a major source of anisotropic hardening of the yield locus of the material.

The evolution of texture has been studied for a commercial DHP copper sheet metal, plastically deformed by the following mechanical tests: uniaxial tension along rolling $\left(0^{\circ}\right)$ and transverse $\left(90^{\circ}\right)$ directions, quasi-plane strain tension $\left(0^{\circ}\right.$ and $\left.90^{\circ}\right)$ and biaxial tension. Two models have been applied to predict the evolution of textures: Viscoplastic under Relaxed Constraints (VRC) (Canova et al., 1985) and a Self Consistent (SC) approach with viscoplastic conditions (Lebensohn et al., 1993). Predictions with the SC model were very close to the experimentally determined textures. The development of a major final texture represented by the $\{110\}<u v w>$ fiber component for biaxial tension is in agreement with the experimental results obtained by S. Kohara (1981).

The evolution of the shape of the yield locus was analyzed by comparing experimental and predicted stress-strain curves along different loading paths and comparing the corresponding yield stresses $\left(\mathrm{P}_{0} / \mathrm{U}_{0}, \mathrm{P}_{90} / \mathrm{U}_{90}\right.$ and $\left.\mathrm{B} / \mathrm{U}_{0}\right)$ at the same level of plastic deformation energy. Predicted curves were calculated utilizing predicted textures.

\section{MATERIAL AND EXPERIMENTAL PROCEDURES}

\section{(a) Material}

The material under study was a commecial $-1 \mathrm{~mm}$ thick-DHP copper sheet $1 / 4$ hard with a mean grain size of $20 \mu \mathrm{m}$. Its mechanical properties are summarized in Table 1.

\section{(b) Mechanical tests}

The following mechanical tests were performed with a 10 ton Instron testing machine:

- Uniaxial tension, with standard tensile specimens, at $0^{\circ}$ and $90^{\circ}$ to the rolling direcion $\left(\mathrm{U}_{0}\right.$ and $\left.\mathrm{U}_{90}\right)$

- Quasi plane-strain tension, with Wagoner type specimens (Wagoner, 1980), at $0^{\circ}$ and $90^{\circ}\left(\mathrm{P}_{0}\right.$ and $\left.\mathrm{P}_{90}\right)$. The Wagoner type specimen is short in the tensile direction 
and wide in the transverse direction, a state of quasi-plane strain is generated in most of the width of it, with the exception of both ends.

- Biaxial tension (B) was performed on a 5 in. diameter specimen with a bulge testing machine.

\section{(c) Experimental determination of crystallographic textures}

A Siemens D500 Goniometer equipped with an Euler Dosophatex sphere was used for the analysis of intensity data by X-ray diffraction using a copper radiation by the reflection technique to a tilt of at least $70^{\circ}$. For each specimen $\{111\},\{110\}$ and $\{100\}$ pole figures were determined. Two different computer programs were utilized to process the data obtained from the goniometer:

- The DACO program corrects experimental intensities obtained by the reflection technique for defocalisation and background, through the use of an Harmonic function it recalculates the pole figures up to $90^{\circ}$.

- The DOSOPHATEX with a program called DOSOPOP, that modifies the POPLA program (J. S. Kallend et al., 1991) to the conditions of the goniometer, corrects the experimental data for defocalisation and background. The POPLA program using an Harmonic function completes the pole figure up to $90^{\circ}$. The Orientation Distribution Function (ODF) was calculated by using the WIMV option (a combination of vectorial and harmonic method) in the POPLA program. The ODF data were utilized to obtain a discrete grains file and to calculate the yield locus.

\section{EXPERIMENTAL RESULTS}

\section{(a) Mechanical properties}

Table 1 shows true stress-true strain curves represented by the parameters $K$ and $n$, obtained by power law regression of equation: $\sigma=K \epsilon^{n}, R$ is the Lankford strain ratio, $\epsilon_{\max }$ and $\epsilon_{\min }$ are limited strains along tensile and transverse directions respectively.

\section{(b) Poles figures}

Figure 1a shows the experimental pole figures of the as received material. Figures 2a to $6 \mathrm{a}$ show pole figures obtained from specimens deformed up to fracture by uniaxial, biaxial and quasi-plane strain tension. Table II shows the principal components of texture $\{h k l\}<u v w>$ and their corresponding weights for different loading paths.

Table 1 Experimental stress-strain curves for uniaxial tension

\begin{tabular}{lccccc}
\hline Test & $K(\mathrm{MPa})$ & $n$ & $R$ & $\epsilon_{\max }$ & $\epsilon_{\text {min }}$ \\
\hline $\mathrm{U}_{0}$ & 476 & 0.255 & 0.63 & 0.485 & -0.178 \\
$\mathrm{U}_{45}$ & 396 & 0.215 & 1.06 & 0.602 & -0.290 \\
$\mathrm{U}_{90}$ & 341 & 0.176 & 0.85 & 0.438 & -0.164 \\
\hline
\end{tabular}


\{111\}
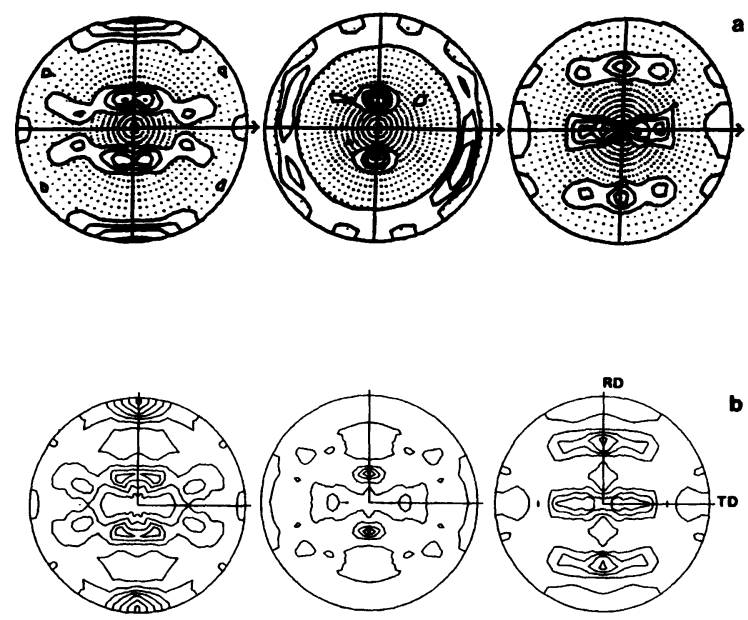

Figure $1\{111\}$ (Max: 4), \{200\} (Max: 4) and \{220\} (Max: 4) pole figures corresponding to the as received Copper sheet. (a) Experimental (b) Reduced orientations.

Table 2 Principal texture components $\{\mathrm{hkl}\}<\mathrm{uvw}>$ and associated weights $(\mathrm{W})$ corresponding to experimental textures ${ }^{(*)}$

\begin{tabular}{|c|c|c|c|c|c|c|}
\hline $\begin{array}{c}\{h k l\} \\
\langle u v w\rangle\end{array}$ & $\begin{array}{l}\text { Initial } \\
W(\%)\end{array}$ & $\begin{array}{c}U_{o} \\
W(\%)\end{array}$ & $\begin{array}{c}U_{90} \\
W(\%)\end{array}$ & $\begin{array}{c}P_{0} \\
W(\%)\end{array}$ & $\stackrel{P_{90}}{W(\%)}$ & $\stackrel{B}{W(\%)}$ \\
\hline $\begin{array}{l}\text { Copper } \\
\{112\} \\
<111>\end{array}$ & 42 & 68 & 16 & 50 & 17 & - \\
\hline $\begin{array}{l}\text { Brass } \\
\{110\} \\
\langle 112\rangle\end{array}$ & 22 & 9 & 50 & 17 & 42 & 66 \\
\hline $\begin{array}{l}\text { Goss } \\
\{110\} \\
<100>\end{array}$ & 25 & 7 & 18 & 17 & - & - \\
\hline $\begin{array}{l}\text { fiber } \\
\{110\} \\
<u v w>\end{array}$ & $\begin{array}{l}47 \\
\text { (1) }\end{array}$ & $\begin{array}{l}16 \\
\text { (1) }\end{array}$ & $\begin{array}{l}68 \\
\text { (1) }\end{array}$ & $\begin{array}{c}34 \\
\text { (1) }\end{array}$ & $\begin{array}{l}67 \\
\text { (2) }\end{array}$ & $\begin{array}{l}83 \\
\text { (3) }\end{array}$ \\
\hline $\begin{array}{l}\text { fiber } \\
\{\text { hkl }\} \\
<111>\end{array}$ & 42 & 68 & 16 & 50 & $\begin{array}{l}42 \\
\text { (4) }\end{array}$ & - \\
\hline
\end{tabular}

(*) Fiber texture includes the following components:

(1): $\{110\}<112>,\{110\}<100>$

(2): $\{110\}<112>,\{110\}<111>,\{110\}<557>$

(3): $\{110\}<112>,\{110\}<332>,\{110\}<557>$

(4): $\{110\}<111>,\{112\}<111>$ 
Quasi-plane strain $\mathrm{P}_{0}$ and uniaxial $\mathrm{U}_{0}$ along rolling directions show the reinforcement of $\{112\}<111>$ Copper component. Biaxial tension B modifies the initial texture to a reinforced $\{110\}$ fiber texture. Quasi-plane strain $P_{90}$ and uniaxial tension $U_{90}$ along transverse direction strengthen the $\{110\}<112>$ Brass component.

\section{ANALYSIS OF TEXTURE EVOLUTION}

\section{(a) Description of initial texture}

For the applications of texture simulation it is necessary to represent an initial discrete set of orientations with their corresponding weights. The WEIGHTS option in the POPLA program transforms an experimental orientation density file into a discrete grains file. It is possible to reduce the number of grains by discarding those with a weight less than some specified value. Figure $1 \mathrm{~b}$ shows pole figures of the initial texture, obtained by the reduced representation procedure. A good agreement with the experimental pole figures (Figure 1a) is observed; it is important to consider that the main components of texture (Table 2) included in the 447 reduced orientations, represent more than $80 \%$ of the total volume.

Texture analysis shows reinforcements around the following orientations: $\{112\}<111>$ (Copper) as a principal component, $\{110\}<112>$ (Brass) and $\{110\}<100>$ (Goss) components.

\section{(b) Prediction of texture evolution}

Two models were utilized to predict the evolution of texture, starting from the reduced orientations representation of the initial experimental texture shown in Figure $1 \mathrm{~b}$ :

- Viscoplastic model under the relaxed constraints assumption (VRC). VRC considers that deformation is accommodated by $\{111\}<110>$ slip systems for f.c.c materials. The introduction of the rate sensitivity in the viscoplastic formulation is done by means of a non linear stress-strain rate constitutive relationship for each slip system $(\mathrm{k})$ :

$$
\dot{\gamma}^{\mathrm{k}} / \dot{\gamma}_{0}^{\mathrm{k}}=\left(\tau^{\mathrm{k}} / \tau_{0}^{\mathrm{k}}\right)^{\mathrm{ns}}
$$

where $\mathbf{n s}$ is the inverse of the strain rate sensitivity, $\tau_{0}^{\mathrm{k}}$ and $\dot{\gamma}_{0}^{\mathrm{k}}$ represent respectively a reference stress and the corresponding reference strain rate for the initial conditions at the slip systems. The shear strain rate $\dot{\gamma}^{\mathrm{k}}$ is determinated by means of the rate of deformation $\dot{\epsilon}_{\mathrm{ij}}$ in each grain. The strain state for each deformation path was described by the $\dot{\epsilon}_{\mathrm{ij}}$ tensor, with principal directions along rolling $\left(0^{\circ}\right)$, transverse $\left(90^{\circ}\right)$ and normal directions, the ratio (-q) of transverse to longitudinal strain was used to describe different loading paths (Mingolo et al., 1993).

The VRC model assumes isotropic hardening of the critical resolves shear stress $\tau_{\mathrm{c}}$ and the relaxed conditions with the hypothesis that some components of stress (Sachs) and some compoenents of strain (Taylor) are imposed. The viscoplastic texture simulations were performed using a value of ns equal to 19.

- The Self consistent formulation with viscoplastic conditions considers the intergranular interaction between each viscoplastic grain and an anisotropic viscoplastic matrix. The deformation of grains is accomodated by the $\{111\}<110>$ slip system. Texture development is related to grain shape evolution during deformation; the self 
consistent relationship between plastic behavior of a grain and the polycrystal is represented by:

$$
\mathbf{M}=\left\langle\mathbf{M}^{\mathrm{c}}\left(\mathbf{M}^{\mathrm{c}}+\tilde{\mathbf{M}}\right)^{-1}(\mathbf{M}+\tilde{\mathbf{M}})>\right.
$$

where $\mathbf{M}$ is the polycrystal viscoplastic compliance modulus, $\mathbf{M}^{\mathrm{c}}$ is the grain viscoplastic compliance modulus and $\tilde{M}$ is the interaction matrix defined by:

$$
\tilde{\mathbf{M}}=-\mathrm{ns}(\mathrm{I}-\mathrm{S})^{-1} \mathrm{~S} \mathbf{M}
$$

considering the viscoplastic Eshelby tensor $\mathrm{S}$ as a function of both: macroscopic modulus $M$ and grain shape.

The interaction equation (4) relates stresses and strains at the levels of grain and polycrystal:

$$
\dot{\epsilon}_{\mathrm{ij}}-\dot{\mathrm{E}}_{\mathrm{ij}}=\tilde{\mathbf{M}}_{\mathrm{ij}}\left(\sigma_{\mathrm{kl}}-\Sigma_{\mathrm{k} 1}\right)
$$

where $\dot{\epsilon}_{\mathrm{ij}}$ and $\sigma_{\mathrm{kl}}$ are strain rate and stress applied to the grain, $\dot{\mathrm{E}}_{\mathrm{ij}}$ and $\sigma_{\mathrm{kl}}$ are strain rate and stress applied to the polycrystal. For the texture simulation ns was taken as 19 .

Figures 2 to 6 show $\{111\},\{200\}$ and $\{220\}$ predicted pole figures. Predictions were performed with the VRC and SC models for material deformed up to the indicated levels of plastic strain under: uniaxial tension (Figures 2 and 3), quasi-plane strain tension (Figures 4 and 5) and biaxial tension (Figures 6).

Comparing experimental and predicted pole figures the following results appear:

- For uniaxial tension $\left(\mathrm{U}_{0}\right)$ (Figures $2 b$ and $2 c$ ) and quasi-plane strain tension $\left(\mathrm{P}_{0}\right)$ (Figures 4b and 4c), both models: VRC and SC produce a good agreement with the experimental results (Figures 2a and 4a); the strong Copper $\{112\}<111>$ component is adequately predicted.

- For the uniaxial tension ( $\left.\mathrm{U}_{90}\right)$ (Figures 3c) and quasi-plane strain $\left(\mathrm{P}_{90}\right)$ (Figures 5c), the SC model gives a good prediction of experimental texture components (Figures $3 a$ and 5a). The VRC formulation (Figures $3 b$ and $5 b$ ) cannot describe the reinforcement of the Brass $\{110\}<112>$ component.

- The experimental texture for biaxial tension (Figures 6a) is well represented by the SC model (Figures 6c), but the VRC model (Figures $6 \mathrm{~b}$ ) does not satisfactorily predict the Brass reinforcement and the others components of the $\{110\}<u v w>$ fiber texture.

\section{CALCULATION OF THE EVOLUTION OF THE YIELD LOCUS}

\section{(a) Description of the yield locus using textural data}

The yield locus of a material is the envelope of hyperplans, tangent to it; each plan corresponds to an imposed strain state $\epsilon_{\mathrm{ij}}$. The yield locus is defined by the following equation in the stress space $\sigma_{\mathrm{ij}}$.

$$
\epsilon_{\mathrm{ij}} \sigma_{\mathrm{ij}}=\tau_{\mathrm{c}} \overline{\mathrm{M}}\left(\epsilon_{\mathrm{ij}}\right) \epsilon_{\mathrm{eq}}
$$

where $\tau_{c}$ is the critical resolved shear stress for slip, identical on all $\{111\}<110>$ systems 

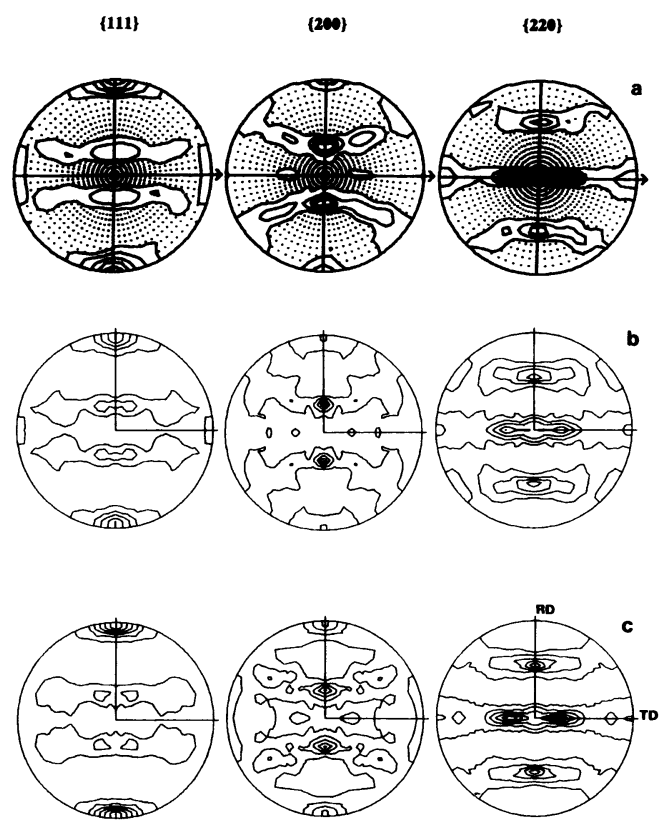

Figure $2\{111\}$ (Max: 8), \{200\} (Max: 4) and \{220\} (Max: 5) pole figures for uniaxial tension along rolling direction, at $\epsilon=0.23$. (a) Experimental. (b) VRC. (c) SC models.
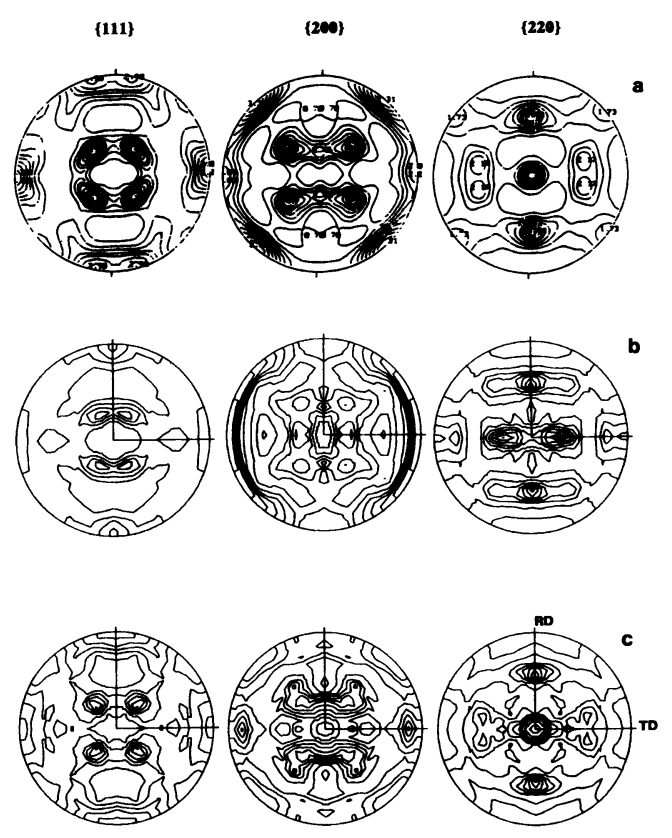

Figure $3\{111\}$ (Max: 4), \{200\} (Max: 4) and \{220\} (Max: 6) pole figures for uniaxial tension along transverse direction, at $\epsilon=0.18$. (a) Experimental (b) VRC. (c) SC. 

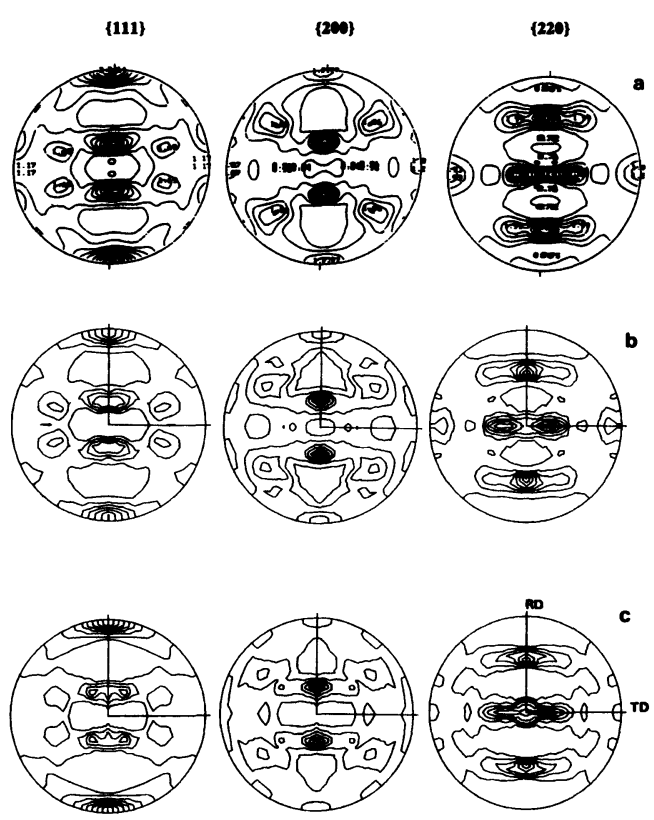

Figure $4\{111\}$ (Max: 4), \{200\} (Max: 4) and \{220\} (Max: 4) pole figures for quasi-plane strain tension along rolling direction, at $\epsilon=0.23$. (a) Experimental (b) VRC. (c) SC.
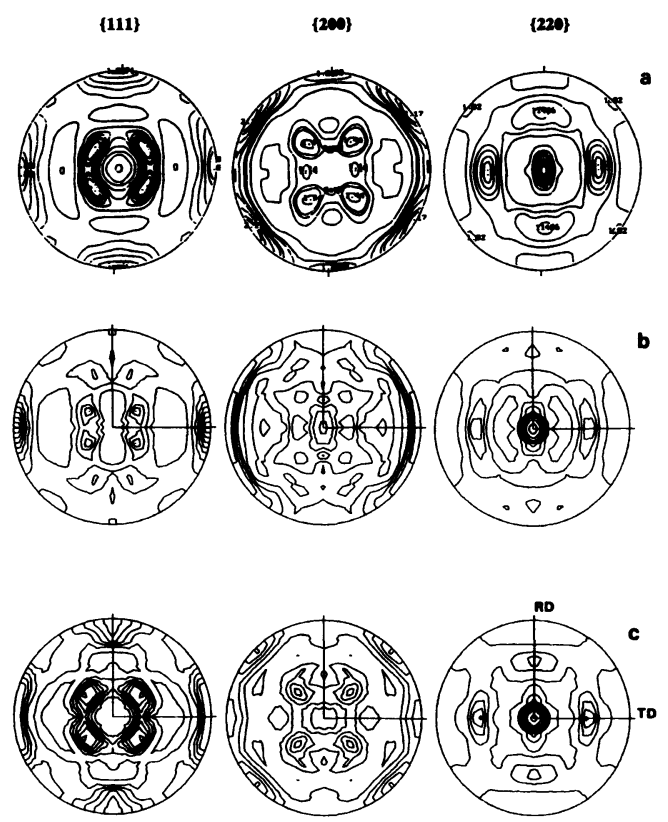

Figure $5\{111\}$ (Max: 2), \{200\} (Max: 2) and \{220\} (Max: 6) pole figures for quasi-plane strain tension along transverse direction, at $\epsilon=0.27$. (a) Experimental. (b) VRC. (c) SC. 

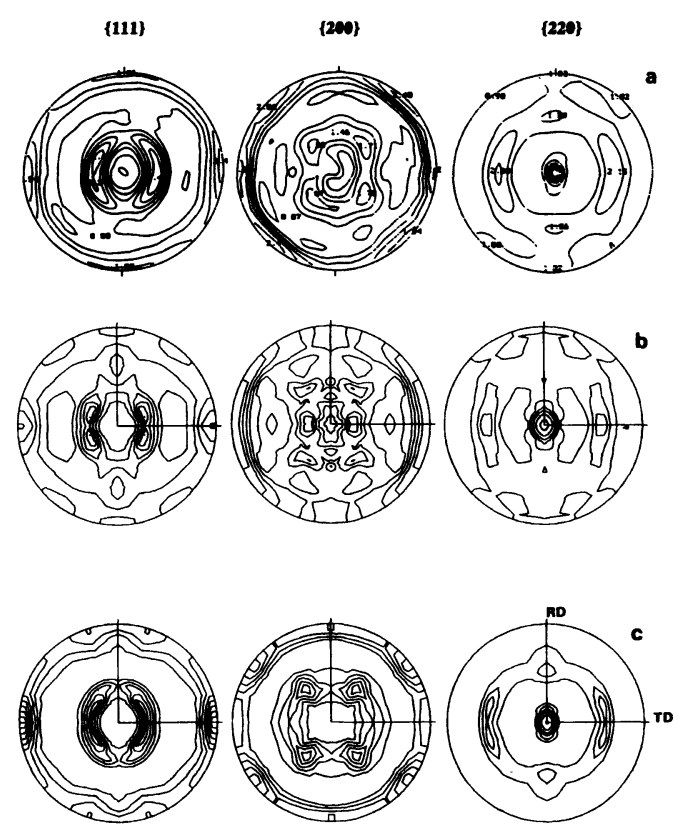

Figure $6\{111\}$ (Max: 3), \{200\} (Max: 2) and \{220\} (Max: 5) pole figures for biaxial tension, at $\epsilon=0.41$. (a) Experimental. (b) VRC. (c) SC.

in f.c.c. materials, $\epsilon_{\mathrm{eq}}$ is the equivalent strain and $\overline{\mathrm{M}}\left(\epsilon_{\mathrm{ij}}\right)$ is the average Taylor factor. by:

Taking into account the texture of the material, the average Taylor factor is calculated

$$
\overline{\mathbf{M}}\left(\epsilon_{\mathrm{ij}}\right)=\int_{\mathrm{g}} \mathbf{M}\left(\epsilon_{\mathrm{ij}}, \mathrm{g}\right) \mathrm{f}(\mathrm{g}) \mathrm{dg}
$$

where $\mathbf{M}\left(\epsilon_{\mathrm{ij}}, \mathrm{g}\right)$ corresponds to the Taylor factor associated to a given grain orientation $g, f(g)$ is the Crystallite Orientation Function (ODF) and $f(g) d g$ defines the volume fraction of cristallites having an orientation between $\mathrm{g}$ and $\mathrm{g}+\mathrm{dg}$.

Equation (6) is calculated taking into account the coefficients of the series expansions: $m_{1 m n}$ for the $M\left(\epsilon_{i j}, g\right)$ calculated for restricted glide $\{111\}<110>$ and $f_{1 m n}$ for $f(g)$. Considering that the simulated texture is represented by a discrete number of orientations with their corresponding weights, it is necessary to transform the discrete representation to an ODF representation, the DIOR and CUBAN2 programs of POPLA code were used to perform this operation.

\section{(b) Predicted and experimental results}

Predicted and experimental true stress-true strain curves for $\mathrm{P}_{0}, \mathrm{P}_{90}$ and $\mathrm{B}$ and shown in Table 3. The predicted curves were calculated utilizing the predicted evolution of textures.

Table 4 (a), (b) and (c) utilize data from Tables 1 and 3 to calculate stress ratios for different loading paths; stresses are compared at the same level of plastic deformation energy. Different levels of plastic strain in uniaxial tension $\in \mathrm{U}_{0}$ or $\in \mathrm{U}_{90}$ were considered. 
Figure 7 compares experimental to predicted true stress-true strain curves obtained in quasi-plane strain tension $\left(\mathrm{P}_{0}\right.$ and $\left.\mathrm{P}_{90}\right)$ and biaxial tension (B) tests. Predicted curves were obtained with VRC and SC models.

Table 3 Experimental and predicted stress-strain curves for quasi plane strain along rolling direction $\left(\mathrm{P}_{0}\right)$ and transverse direction $\left(\mathrm{P}_{90}\right)$ and biaxial tension $(\mathrm{B})$.

\begin{tabular}{lccc}
\hline$P_{0}$ & Experimental & $V R C$ & $S C$ \\
\hline $\mathrm{K}(\mathrm{MPa})$ & 467.00 & 471.99 & 470.55 \\
$\mathrm{n}$ & 0.196 & 0.238 & 0.212 \\
$P_{90}$ & Experimental & $V R C$ & $S C$ \\
$\mathrm{~K}(\mathrm{MPa})$ & 410.00 & 351.96 & 403.30 \\
$\mathrm{n}$ & 0.181 & 0.169 & 0.187 \\
$B$ & Experimental & $V R C$ & $S C$ \\
$\mathrm{~K}(\mathrm{MPa})$ & 461.00 & 706.81 & 478.77 \\
$\mathrm{n}$ & 0.254 & 0.270 & 0.252 \\
\hline
\end{tabular}

Table 4 Stress ratios for experimental and predicted stress-strain curves. $\in \mathrm{U}_{0}$ : uniaxial deformation along rolling direction, $\in \mathrm{U}_{90}$ : uniaxial deformation along transverse direction. (a): Plane strain along rolling direction $\left(\mathrm{P}_{0}\right)$ (b): Plane strain along transverse direction $\left(\mathrm{P}_{90}\right)$ (c): Biaxial tension (B)

\begin{tabular}{lccc}
\hline$(a)$ & & $P_{d} / U_{0}$ & \\
\cline { 2 - 4 }$\epsilon \mathrm{U}_{0}$ & Experimental & $\mathrm{VRC}$ & $\mathrm{SC}$ \\
0.10 & 1.093 & 1.022 & 1.070 \\
0.15 & 1.071 & 1.016 & 1.052 \\
0.20 & 1.056 & 1.012 & 1.042 \\
0.25 & 1.045 & 1.009 & 1.034 \\
0.30 & 1.035 & 1.006 & 1.027 \\
0.35 & 1.028 & 1.004 & 1.021 \\
0.40 & 1.021 & 1.003 & 1.016 \\
\hline$(b)$ & & $P_{90} / U_{90}$ & \\
\hline & & $\mathrm{VRC}$ & $\mathrm{SC}$ \\
$\epsilon \mathrm{U}_{90}$ & Experimental & 1.041 & 1.129 \\
0.10 & 1.158 & 1.038 & 1.133 \\
0.15 & 1.160 & 1.036 & 1.136 \\
0.20 & 1.161 & 1.035 & 1.138 \\
0.25 & 1.163 & 1.034 & 1.140 \\
0.30 & 1.164 & 1.033 & 1.142 \\
0.35 & 1.164 & 1.032 & 1.144 \\
0.40 & 1.165 & $B / U_{o}$ & \\
\hline$(c)$ & & $\mathrm{VRC}$ & $\mathrm{SC}$ \\
$\epsilon \mathrm{U}_{0}$ & Experimental & 1.331 & 1.009 \\
0.10 & 0.976 & 1.337 & 1.008 \\
0.15 & 0.976 & 1.342 & 1.007 \\
0.20 & 0.975 & 1.346 & 1.007 \\
0.25 & 0.975 & 1.348 & 1.006 \\
0.30 & 0.975 & 1.351 & 1.006 \\
0.35 & 0.975 & & \\
0.40 & 0.975 & &
\end{tabular}


(c) Analysis of Results

The anisotropy in the plane of the sheet is related to the deformation path. Tables 1 and 3 show a considerable lower strain hardening exponent for uniaxial tension $\left(U_{90}\right)$ and quasi-plane strain tension $\left(\mathrm{P}_{90}\right)$ along transverse direction than the corresponding curves in the rolling direction.
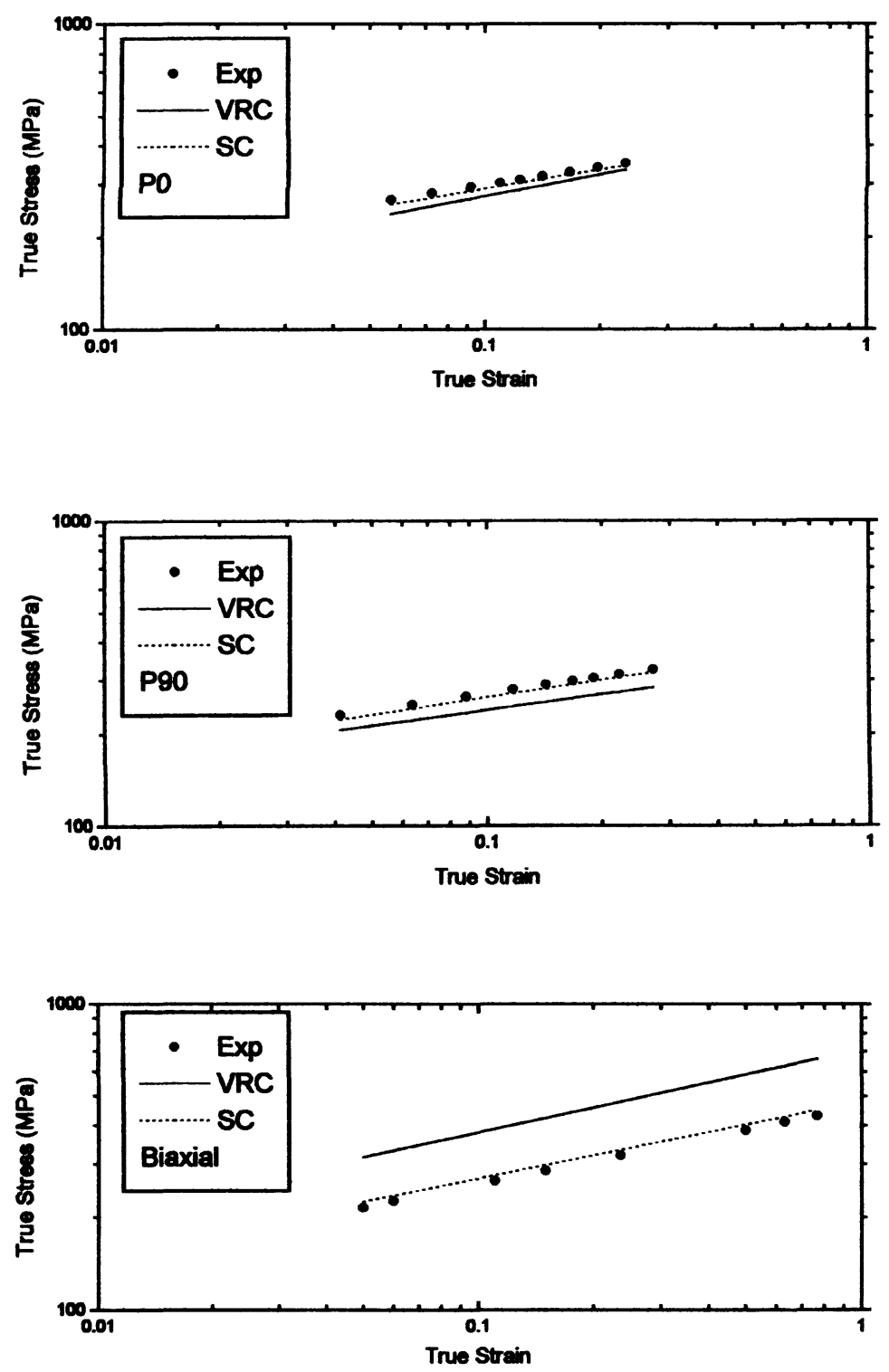

Figure 7 True stress-true strain curves. Experimental and predicted with VRC and SC models. (a) $\mathrm{P}_{0}$, (b) $\mathrm{P}_{90}$, (c) Biaxial. 
Table 3 and Figure 7 show that the SC model gives very close predictions for $\mathbf{P}_{0}$, $\mathrm{P}_{90}$ and $\mathrm{B}$; by contrast, predictions with the VRC model are accurate only for $\mathrm{P}_{0}$ but they are poor for $\mathrm{P}_{90}$ and $\mathrm{B}$. Besides, the strain hardening predicted by the VRC model is considerably different from experimental data.

\section{CONCLUSIONS}

- The reduced representation of the initial texture (447 orientations), obtained by using the WEIGHTS program, accurately describes the experimental pole figures for a commercial copper sheet.

- The VRC model is only capable to predict the texture evolution during plastic deformation along rolling direction $\left(\mathrm{U}_{0}\right)$ and $\left(\mathrm{P}_{0}\right)$.

- At strains lower than 0.5 and small grains, the SC model adequately predicts the evolution of textures for tension tests: along rolling direction $\left(\mathrm{U}_{0}\right.$ and $\left.\mathrm{P}_{0}\right)$, along transverse direction $\left(\mathrm{U}_{90}\right.$ and $\left.\mathrm{P}_{90}\right)$ and biaxial tension (B).

- Predictions with SC model show the influence of some self-organization scheme, related with the possibility to follow the grain shape evolution, on the texture evolution with different deformation paths.

- The SC model -including the corresponding texture evolution- gave accurate predictions of the stress-strain curves for $\mathrm{P}_{0}, \mathrm{P}_{90}$ and $\mathrm{B}$; by contrast predictions with the VRC model were considerably different from the experimental data for $\mathrm{P}_{90}$ and B.

\section{Acknowledgements}

The experimental results of textures were obtained by Pierre Gerbert at the Laboratory LM3 - ENSAM, Paris-France. We wish to thank the support received by: Dr Jean Lou Lebrun, Laboratory LM3-ENSAM-Paris-France; Department de Materiales de la Comisión de Energía Atómica, Argentina; Multinational Project of Materials, American States Organization and Project 89-0673 FONDECYT, CONICYT-CHILE.

\section{References}

Canova, G. R., Kocks, U. F., Tomê, C. N. and Jonas J. J. (1985). J. Mech. and Phys. Solids, 33, 371.

Kallend, J. S., Kocks, U. F., Rollet, A. D. and Wenk, H. R. (1991). Mat. Science and Eng., A132, 1.

Kohara, S. (1981). Proc. ICOTOM 6, 300.

Lebensohn, R. A. and Tomé, C. N. (1993). Acta metall. mater., 21, 2611.

Mingolo, N., Vial Edwards, C. and Pochettino, A. A. (1993). Textures and Microstructures, 21, 207.

Wagoner, R. H. (1980). Metallurgical Transactions A, 11A, 165. 